\title{
A Study on Nitrate Ion Reduction in Water with Zero-Valent Iron Loaded Nano-Titania Prepared from IImenite Ore
}

\author{
M.H.H.MAHMOUD ${ }^{1,2, *}$ \\ ${ }^{1}$ Materials Science \& Engineering Group, Chemistry Department, \\ College of Science, Taif University, Taif, Kingdom of Saudi Arabia. \\ ${ }^{2}$ Central Metallurgical Research and Development Institute, P.O.Box, 87, \\ Helwan, Cairo, Egypt. \\ ${ }^{*}$ Correponding author E-mail : mheshamm @ gmail.com \\ http://dx.doi.org/10.13005/ojc/320424
}

(Received: December 28, 2015; Accepted: June 02, 2016)

\begin{abstract}
This paper aims to synthesize titanium dioxide loaded with nano-zero valent iron (nZVI-TiO $)$ from an inexpensive ilmenite ore. Ilmenite leachant, a solution rich in both titanium and iron ions, has been prepared by leaching ilmenite ore in hydrochloric acid. At $30 \% \mathrm{HCl}, 70^{\circ} \mathrm{C}$ and 5 hours, almost all of iron and titanium in the ilmenite ore were dissolved. Nano titania was then produced by hydrolysis of the IImenite leachant in boiling water under open atmosphere and nano-zero valent iron (nZVI) was subsequently precipitated on its surface by reduction with sodium borohydride. The synthesized nZVI-TO ${ }_{2}$ was characterized by TEM, UV-Vis absorption, XRD and EDXRF and tested for reduction of nitrate ion from water. The synthesized material showed good performance in reduction of nitrate ion in water compared with nZVI.About $40 \%$ of nitrate ion could be removed using $\mathrm{nZVI}-\mathrm{TO}_{2}$ from nearly neutral water after 3 hours.
\end{abstract}

Keywords: Nitrate ion, Reduction, Nano- Zero valent Iron, Ilmenite ore.

\section{INTRODUCTION}

Nitrate ion are considered as hazardous environmental contaminants of ground and surface water. According to the US Environmental Protection Agency (EPA), nitrate ion threshold concentration in drinking water should not exceed $10 \mathrm{mg} / \mathrm{Lit}{ }^{1}$. However, this threshold level is surpassed in many cases due to many reasons, the most important being due to the intensive and uncontrolled use of fertilizers in agriculture ${ }^{2}$. Unfortunately, nitrate ions may persist for decades in groundwater and accumulate to high levels as more nitrogen based fertilizers are fed to the soil each year ${ }^{3}$. Various techniques have been adopted so far for drinking water denitrification: ion-exchange, reverse osmosis, adsorption, biological denitrification and chemical reduction ${ }^{4-6}$. These techniques have their advantages and disadvantages. Ion exchange and reverse osmosis suffer from a medium to high 
operating cost due to the frequent regeneration of the media and production of secondary brine waste. Adsorption by ion exchangers suffers from strong $\mathrm{pH}$ and temperature dependency and spent adsorbent disposal problem 7 . Biological denitrification has a lower operating cost and is the prevalent method used for the moment. It suffers from excessive biomass and soluble microbial by-products. In addition, this process is relatively slow and, compared to the chemical reduction method, sometimes suffer from incomplete removal of nitrate ion ${ }^{8}$.

Nano sized zero valent metals possess a high specific surface area and a high surface reactivity. A technical problem associated with the industrial application of such materials is that they cannot be used alone and should be supported. Pillared clays and zeolites have been recently used as low cost effective supports for nano-scale zero valent iron ${ }^{9}$.Nano-sized support materials for zero valent iron can help in increasing the surface area without agglomeration. Nano titania is suggested to be a suitable support due to its high chemical stability at different aqueous media. In this work, ilmenite ore has been used to prepare nano-titania.

Natural ilmenite is an inexpensive raw material contains varieties of components such as $\mathrm{TiO}_{2}, \mathrm{FeO}, \mathrm{Fe}_{2} \mathrm{O}_{3}$ and $\mathrm{SiO}_{2}$. The extraction methods of titanium from ilmenite can be summarized into two categories; pyrometallurgical and hydrometallurgical routes. Hydrochloric acid leaching is much simpler and the residual acid can be recycled to the process $^{13-16}$. The titanium acidic solution shouldbe further purified and hydrolyzed to produce pure $\mathrm{TiO}_{2}{ }^{14}$.

We have previously utilized an Egyptian ilmenite ore for preparation of nano-titania by acid leaching, purification for separation of iron and hydrolysis. The prepared material was used as a catalyst loaded with different metal ions for removal of varieties of pollutants in water ${ }^{15,16}$.

Since zero-valent iron $(\mathrm{Fe}(0))$ was first acknowledged as a treatment medium for environmental remediation nearly two decades ago ${ }^{17}$, it has been advanced into a viable and attractive option for treatment of many types of organic and inorganic contaminants ${ }^{18}$. Removal of contaminants by $\mathrm{Fe}(0)$ occurs via several physicochemical processes including chemical reduction, specific and nonspecific adsorption and coprecipitation. Ryu et al. ${ }^{19}$ demonstrated the utility of nano zero valent $(\mathrm{nZVI})$ iron for nitrate ion reduction, highlighting the potential effect of particle aggregation and catalyst. Given the various limitations of $\mathrm{Fe}(0)$-based treatment systems, the successful removal of contaminants primarily depends on how well the reactivity of $\mathrm{Fe}(0)$ can be sustained for a longer period of time. Sustained reactivity of $\mathrm{Fe}(0)$ can be maintained by compensating hydrogen ions consumed during the reaction or by minimizing surface passivation by iron corrosion products. Numerous efforts to enhance performance of $\mathrm{Fe}(0)$ have been made in recent years, with the most involving amendment of various additive materials into $\mathrm{Fe}(0)$ reactions ${ }^{20}$.

This work aims to present a new material for the chemical reduction of nitrate ion using an ilmenite ore for preparation of nano-titanium dioxide to be used as a support for the nZVI. Leaching of ilmenite in hydrochloric acid produced solution rich in both titanium and iron ions. The effects of conditions of titanium dissolution from natural ilmenite and hydrolysis were systematically studied. Thus, nZVI prepared by subsequent reduction of iron ions in the same solution. This is to promote the performance and stability of zero valent iron in reduction of nitrate ion by supporting it on nano titania. In this way, the prepared material benefits from enhanced chemical reactivity by keeping the iron particles without agglomeration. The effect of different loadings of zero valent $\mathrm{Fe}$, solution initial $\mathrm{pH}$ and time on the nitrate ion anion removal were investigated.

\section{EXPERIMENTAL}

\section{Materials and Instruments}

A representative sample of $10 \mathrm{~kg}$ ilmenite ore from Abu Ghalaga region, Red Sea, Egypt, was thoroughly mixed, crushed and ground to $100 \%$ -200 . The chemical analysis of the ilmenite sample, was determined using X-ray fluorescence (XRF), and was given in Table 1.Chemicals of analytical grade were used for the extraction and synthesis (hydrochloric acid $\mathrm{HCl} 37 \%$ Sigma Aldrich, sulfuric acid $98 \%$ Sigma Aldrich, sodium borohydride $\mathrm{NaBH}_{4}$ $(\mathrm{BDH})$, ethanol 99\%Sigma Aldrich, $\mathrm{NaOH} 99 \%$, $\mathrm{NaNO}_{3} 99 \%$. Nitrate ion reagent was obtained from 
Hack company (USA) and used for determination of nitrate ion by spectrophotometer DR6000, Hack (USA). Double distilled water was used during the whole work.

Chemical analysis of the ore was carried out by X-ray fluorescence (XRF) using Quant'xEnergy Dispersive-XRF Spectrometer. Chemical analysis of $\mathrm{Fe}$ ions in aqueous solutions was carried out using Atomic Absorption Spectrometer Model Perken-Elmer 3100. Titanium was determined spectrophotometrically by the hydrogen peroxide method at wavelength $410 \mathrm{~nm}^{24}$. X-ray diffraction (XRD) patterns was obtained using an automated

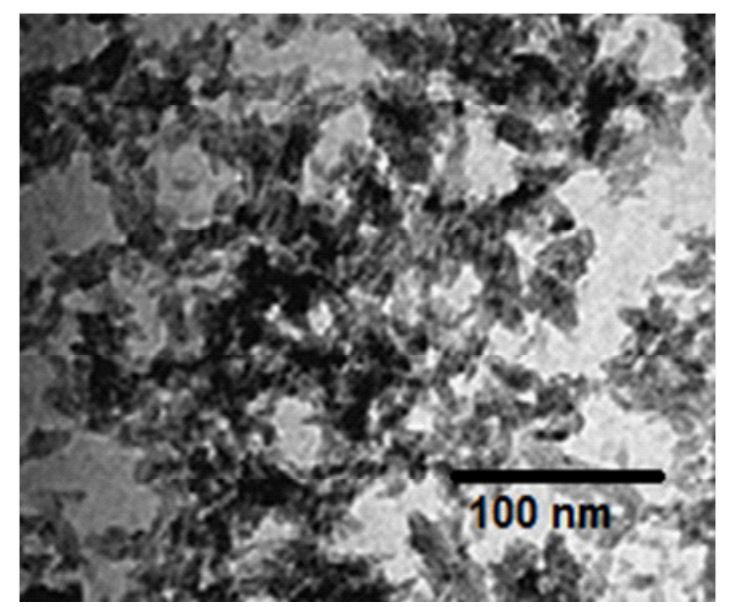

Fig. 1: TEM image of nanotitania (x 10000) magnifications
diffractometer(Philips type: PW1840), at a step size of $0.02^{\circ}$, scanning rate of $2^{\circ}$ in $2 \theta / \mathrm{min}$, and a $2 \theta$ range from $4^{\circ}$ to $80^{\circ}$. Semi-quantitative phase analysis was performed applying X'PertHighScore Plus software.

\section{Leaching of Ilmenite Ore}

For studying the different parameters affecting the dissolution of titanium and iron from ilmenite, small scale experiments were firstly applied. A $20 \mathrm{~g}$ ilmenite ore was inserted into a Pyrex flask reactor provided with a reflux condenser. A $200 \mathrm{~mL}$ hydrochloric acid solution of a desired concentration was added and the mixture was magnetically stirred at $400 \mathrm{rpm}$ under a reflux condition for a period of time from 1 to 6 hours. The system was heated to the desired temperature ( from $25^{\circ} \mathrm{C}$ to to $103^{\circ} \mathrm{C}$ ) using a thermostatically controlled glycerol/water bath. The obtained slurry was filtered off using a vacuum Buchner filtration system and the residue was washed with $1 \% \mathrm{HCl}$ and the wash liquor was mixed with the first filtrate.IImenite leachant rich in titanium and iron was produced.

The percent of titanium or iron extraction was calculated by the following formula:

$$
\mathrm{E} \%=\left(\frac{V \cdot C}{G \cdot P}\right) \cdot 100
$$

where $\mathrm{E} \%$ is the $\mathrm{Ti}$ or Fe extraction,\%, C

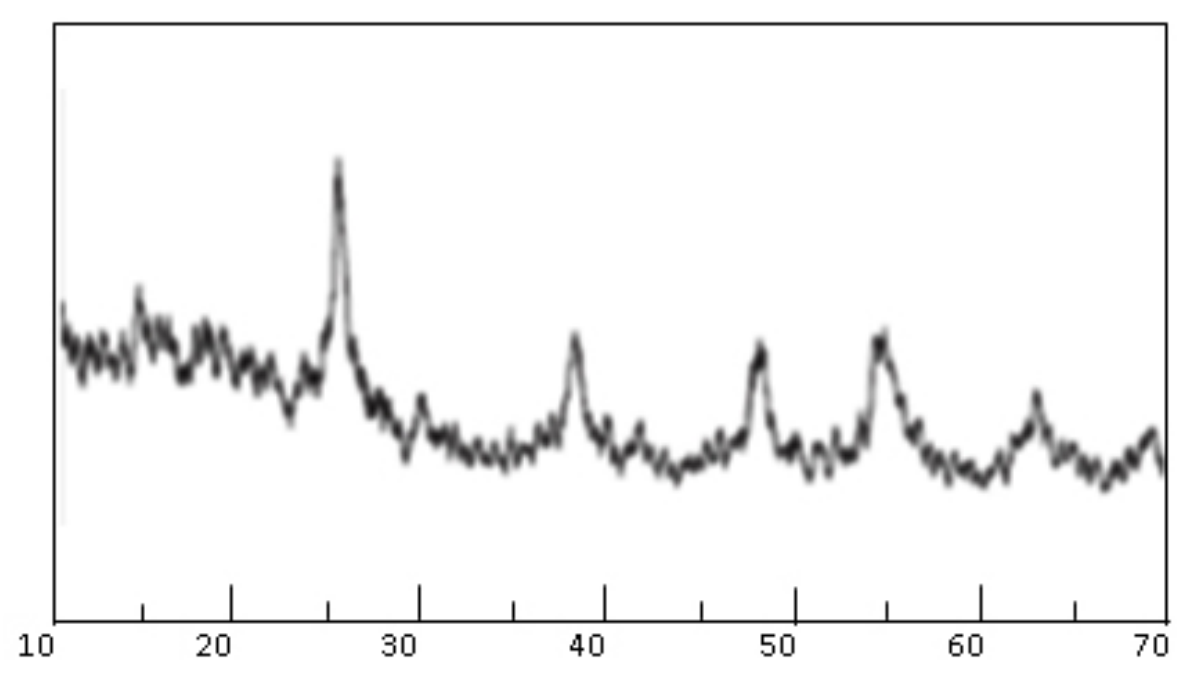

$2 \theta$

Fig. 2: X-ray diffraction pattern of titanium dioxide particles hydrolyzed from ilmeniteleachant 
is the Ti or Fe concentration in the leachant ( $\mathrm{g} / \mathrm{L}), \mathrm{V}$ is the volume of leachant (liters), $\mathrm{G}$ is the total mass of the ore $(\mathrm{g})$ and $\mathrm{P}$ is the Ti or Fe concentration in the ore.

\section{Synthesis of nZVI Loaded on Hydrated Titania Prepared from IImenite}

A larger scale leaching experiment of the Ilmenite Ore was performed to produce sufficient amount of the solution rich in titanium and iron at the optimum leaching conditions. In this case a 200 $\mathrm{g}$ ilmenite was mixed with $2000 \mathrm{~mL}$ hydrochloric acid at the optimum conditions of time and temperature under reflux condition. Hydration of titanium was performed as follows : in a $5000 \mathrm{~mL}$ Pyrex glass beaker, $4000 \mathrm{~mL}$ distilled water was added and

Table 1: Chemical composition of ilmenite concentrate

\begin{tabular}{lc}
\hline Component & Weight, \% \\
\hline $\mathrm{TiO}_{2}$ & 41.95 \\
$\mathrm{Fe}_{2} \mathrm{O}_{3}$ (equivalent) & 53.83 \\
$\mathrm{SiO}_{2}$ & 2.18 \\
$\mathrm{CaO}$ & 0.06 \\
$\mathrm{MgO}$ & 0.83 \\
$\mathrm{Al}_{2}$ & 1.07 \\
$\mathrm{MnO}_{3}$ & 0.27 \\
$\mathrm{~V}_{2} \mathrm{O}_{5}$ & 0.025 \\
\hline
\end{tabular}

heated near boiling and then $100 \mathrm{~mL}$ ilmenite leachant was added and stirred magnetically. Iron powder (by the ratio $0.05 \mathrm{~g} / \mathrm{ml}$ ilmenite leachant) was mixed in order to reduce almost ferric ions to ferrous ions. Once this reduction was completed, the yellowish color of ferric chloro complex turned to colorless and the hydration started immediately. A white turbidity developed with time indicating the precipitation of the hydrated titanium dioxide $\left(\mathrm{TiO}_{2}\right.$. $\mathrm{xH}_{2} \mathrm{O}$ ). The mixture was left at $70^{\circ} \mathrm{C}$ for 2 hours for completion of hydration process. The produced suspension is cooled down to room temperature and the $\mathrm{pH}$ was adjusted to 2.0 by adding $0.1 \mathrm{~N} \mathrm{NaOH}$.

Precipitation of $\mathrm{nZVI}$ on hydrated titanium dioxide was performed as follows : the whole produced amount of hydrated titanium dioxide was vigorously mixed under $\mathrm{N}_{2}$ atmosphere at ambient temperature. A $150 \mathrm{~mL}$ of a $0.2 \mathrm{M}$ aqueous solution of $\mathrm{NaBH}_{4}$ was added dropwise where a black precipitate of iron was immediately appeared and the suspension turned black. The slurry was filtered off using vacuum pump and the precipitated powder was washed several times with absolute ethanol and then dried at $80^{\circ} \mathrm{C}$ for 24 hours.

The ferrous iron was reduced by the borohydride through the reaction shown in Eq. $(1)^{22}$ :

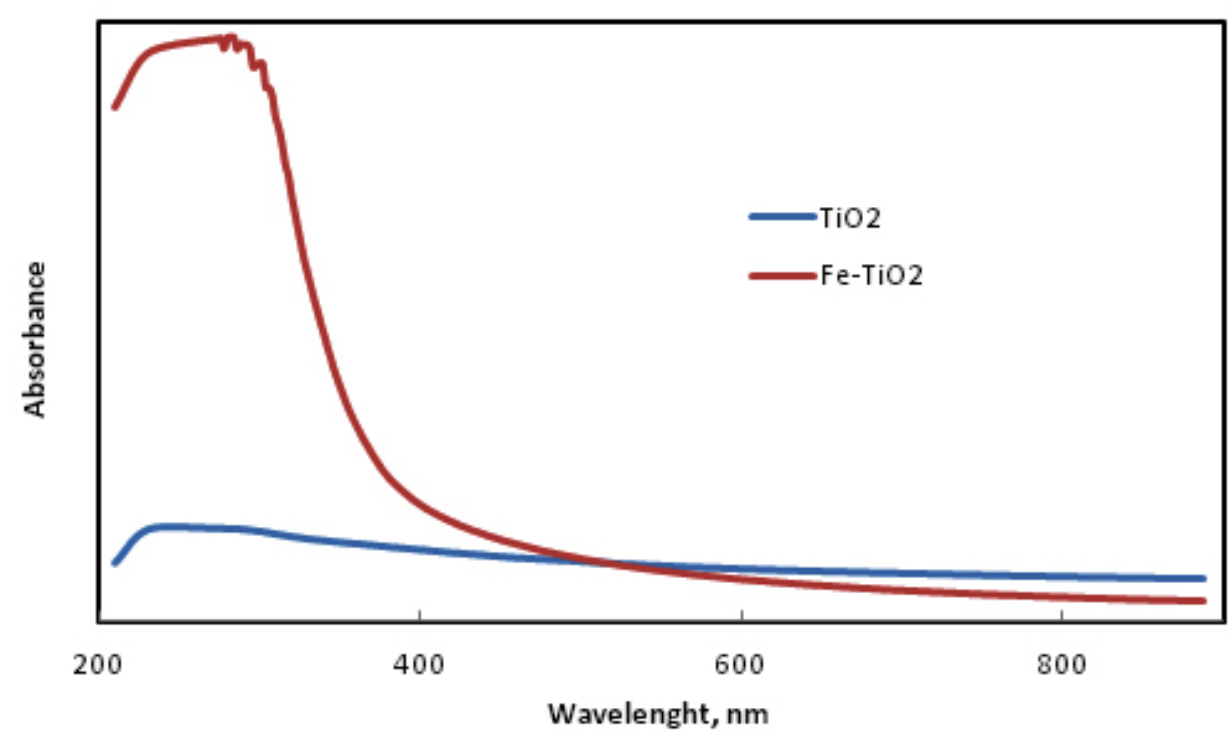

Fig. 3: UV-Vis absorbance of synthesized $\mathrm{TiO}_{2}$ and $\mathrm{Fe}-\mathrm{TiO}_{2}$ and the $\mathrm{ZVI-TiO}$ 
$\mathrm{Fe}\left(\mathrm{H}_{2} \mathrm{O}\right)_{6}{ }^{2+}+2 \mathrm{BH}_{4}-\rightarrow \mathrm{Fe}^{0}+2 \mathrm{~B}(\mathrm{OH})_{3}+7 \mathrm{H}^{2} \uparrow$

\section{Synthesis of $n Z V I$ from Ferrous Sulfate}

A $100 \mathrm{~mL}$ of $0.04 \mathrm{M}$ aqueous solution of $\mathrm{FeSO}_{4} \cdot 7 \mathrm{H}_{2} \mathrm{O}$ was added to a three-necked flask and vigorously mixed by a mechanical stirrer fitted with a glass rod under an atmosphere of $\mathrm{N}_{2}$ and at ambient temperature. $\mathrm{A} 100 \mathrm{~mL}$ of a $0.2 \mathrm{M}$ aqueous solution of $\mathrm{NaBH}_{4}$ was then added, dropwise, to the flask. The slurry was filtered off using vacuum pump and the precipitated powder was washed several times with absolute ethanol and then dried at $80^{\circ} \mathrm{C}$ for 24 hours.

\section{Nitrate lon Reduction}

Reduction of nitrate ion was studied using $\mathrm{nZVI}$ alone and $\mathrm{nZVI}$ loaded on hydrated $\mathrm{TiO}_{2}$. Weighed amounts of the synthesized material was added into glass vials containing $10 \mathrm{~mL}$ of $50 \mathrm{mg} / \mathrm{L}$ sodium nitrate ion at neutral $\mathrm{pH}$ and the solutions

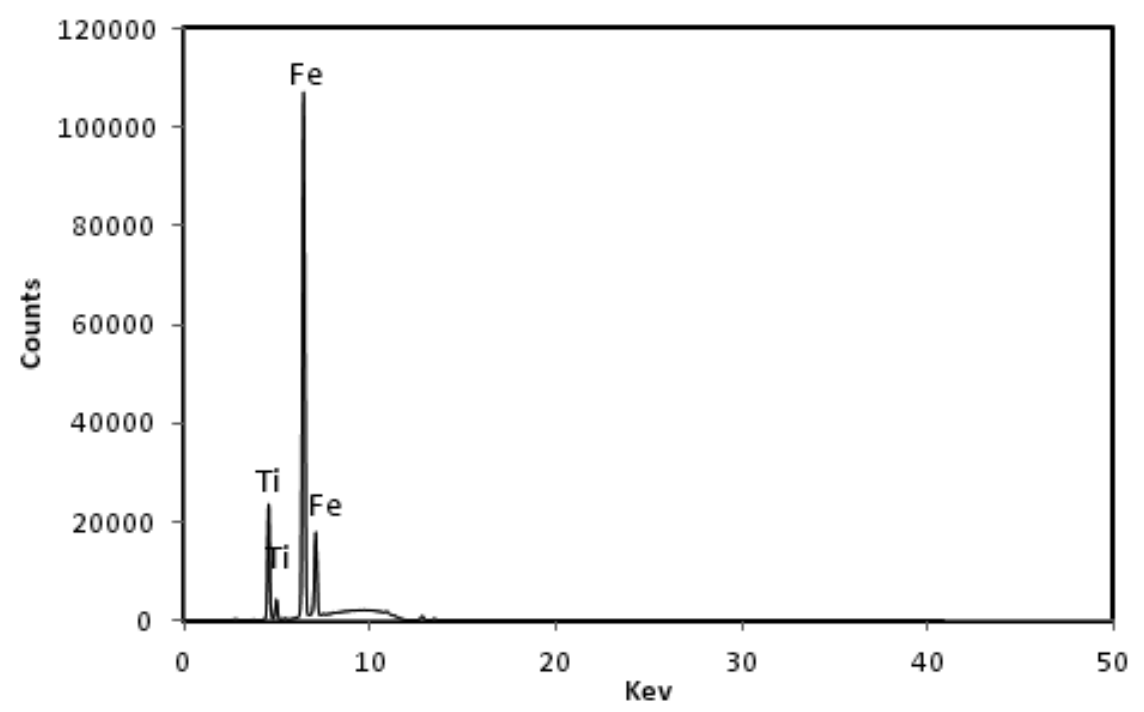

Fig. 4: EDXRF spectrum of the synthesized nZVI-TiO

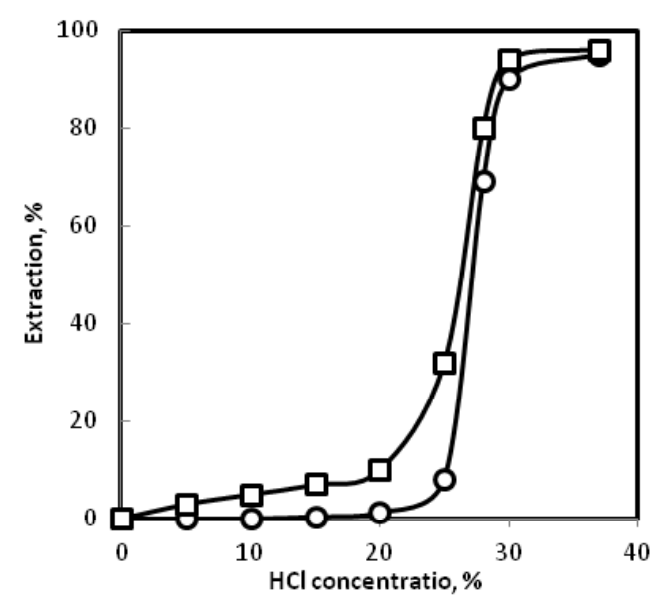

Fig. 5 : Effect of hydrochloric acid concentration on leaching of titanium and iron from ilmeniteore. $(\square)$ iron and (o) titanium

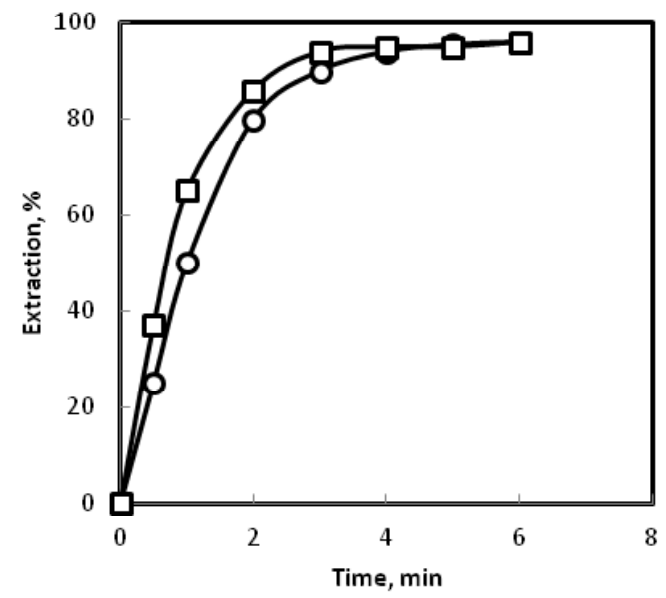

Fig. 6: Effect of time on leaching of titanium and iron from ilmeniteore. ( $\square$ ) iron and (o) titanium 
were shaken for the required period of time at speed of $150 \mathrm{rpm}$ at room temperature. After the desired time passed, the suspensions were filtered using vacuum pump and the nitrate concentrations were measured. The nitrate ion removal efficiency were calculated according to the following formula :

$$
\% \mathrm{R}=\left(\frac{C_{0} \cdot C_{e}}{C_{0}}\right) \cdot 100
$$

where $\mathrm{Co}, \mathrm{Ce}$ are the initial and the equilibrium nitrate ion concentration, respectively.

\section{RESULTS AND DISCUSSION}

\section{Characterization of the Synthesized Materials}

Characterization of the synthesized materials were investigated using TEM, XRD, UVvis and EDXRF. TEM micrograph of nanotitania that was hydrolyzed from ilmenite ore leachant is presented in Fig. 1. Inspecting these micrographs revealed the formation of distinct leaf-like morphology nanocrystals with average diameter of $20 \mathrm{~nm}$. It is possible to see the 'leafy' morphology. These 'leaves' dispersing evenly in solution so that it is stable more than 6 months at room temperature ${ }^{23}$. The particles looked dispersed homogeneously without agglomeration.

The X-ray diffraction pattern of titanium dioxide particles prepared by hydrolysis of the ilmenite leachant at $100{ }^{\circ} \mathrm{C}$ without any further heat

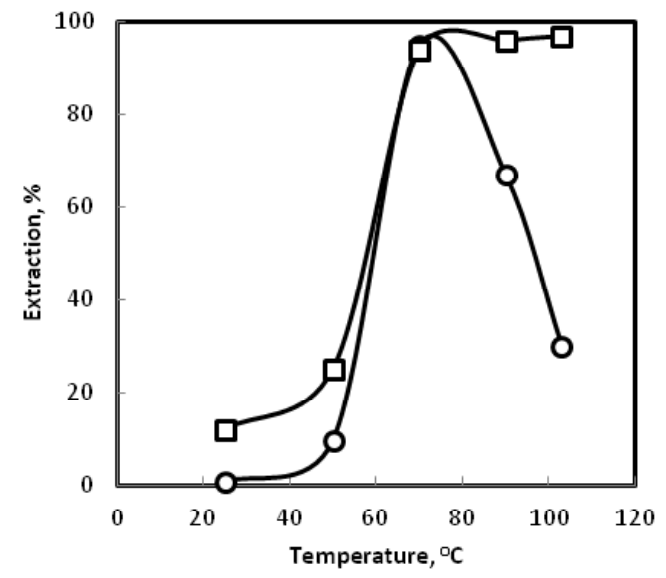

Fig. 7: Effect of temperature on leaching of titanium and iron from ilmeniteore. ( $\square$ ) iron and (o) titanium

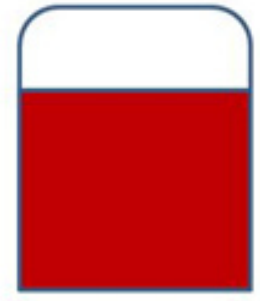

IImenite leachate
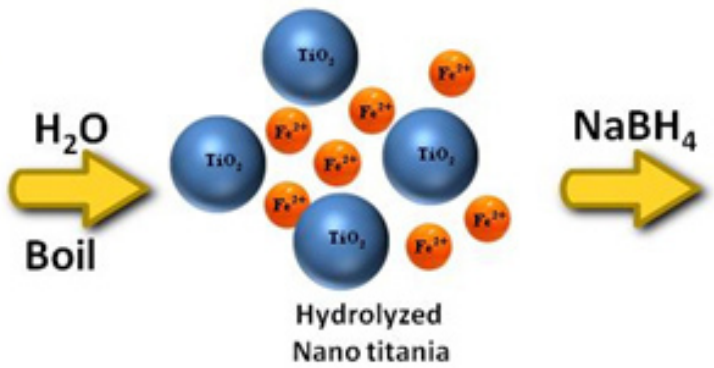

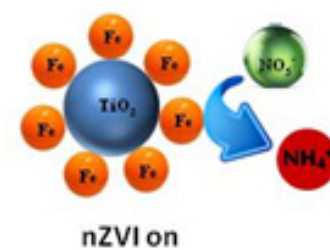

Nano titania

Fig. 8: Schematic diagram of synthesis of $\mathrm{nZVI}$ loaded $\mathrm{TiO}_{2}$ and nitrate ion reduction

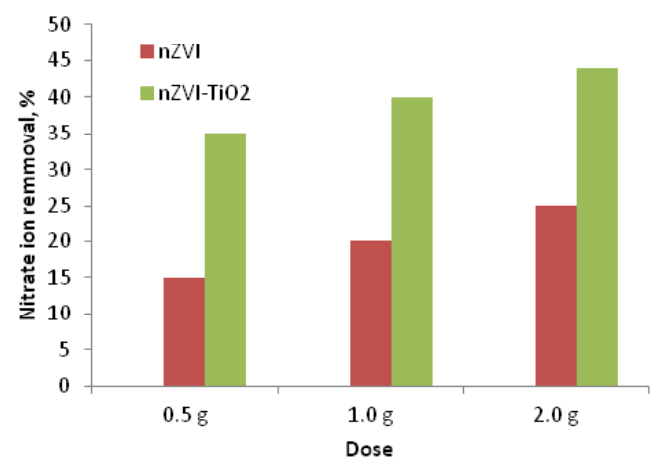

Fig. 9: Nitrate ion reduction by $\mathrm{nZVI}$ and nZVI-TiO ${ }_{2}$ at $\mathrm{pH} 7$ for 3 hours treatment is shown in Fig. 2. Only anatase phase $\mathrm{TiO}_{2}$ was detected as the main hydrolysis product. This results agrees well with our previous work where a purified $\mathrm{TiOCl}_{2}$ is hydrolyzed at similar conditions ${ }^{23}$.

The UV-Vis optical absorption of the hydrolyzed titania and nZVI loaded titania are presented in Fig. 3. The hydrolyzed titania showed sharp absorption band towards the UV region $(<400$ $\mathrm{nm}$ ). However, this absorption band was absent after loading the titania with nZVI. This may be due to the adhesion of nano iron particles on titania 
surface making isolating layers those are blocking any interaction of the light beams with $\mathrm{TiO}_{2}$ surface. This may suggest that nZVI-titania particles will chemically react with the targeted nitrate ions without any catalytic or photocatalytic effect of the $\mathrm{TiO}_{2}$ support.

The synthesized $\mathrm{nZVI-TiO}$, was investigated using EDXRF. Figure 4 showed that the synthesized material contains about $40 \% \mathrm{Fe}$ and $10 \% \mathrm{Ti}$.

\section{Studying Leaching Conditions of IImenite Ore}

Natural ilmenite is an inexpensive raw material contains varieties of components. The major ones are $\mathrm{TiO}_{2}$ and iron oxides. Table 1 shows an example of the chemical composition of an Egyptian low grade ilmenite ore that is used in this work. It contains a low content of $\mathrm{TiO}_{2}$ of about $42 \%$, and a high content of total Fe of about 38\%. Though, it is considered as a low grade ilmenite ore. The extraction procedures aims at maximum dissolution of titanium and iron contents in the leachant. The rich leachant will be then utilized as a source for synthesis of nZVI loaded on titanium dioxide.

It is known that the main minerals in ilmenite ore are ilmenite $\left(\mathrm{FeTiO}_{3}\right.$ or $\left.\mathrm{FeO} . \mathrm{TiO}_{2}\right)$ which contain iron in the divalent state and titanium in the tetravalent state, and hematite $\left(\mathrm{Fe}_{2} \mathrm{O}_{3}\right)$ which contain iron in the trivalent state ${ }^{13}$. The ilmenite fraction in the ore is dissolved in hydrochloric acid as follows:

$\mathrm{FeO} \cdot \mathrm{TiO}_{2}+4 \mathrm{HCl} \rightarrow \mathrm{FeCl}_{2}+\mathrm{TiOCl}_{2}+\mathrm{H}_{2} \mathrm{O}$

and the hematite fraction in the ore is dissolved in hydrochloric acid as follows:

$\mathrm{Fe}_{2} \mathrm{O}_{3}+6 \mathrm{HCl} \rightarrow 2 \mathrm{FeCl}_{3}+3 \mathrm{H}_{2} \mathrm{O}$

Thus, the resulting leachant would contain $\mathrm{Fe}^{2+}, \mathrm{Fe}^{3+}$ and $\mathrm{Ti}^{4+}$ ions together with some metallic impurities (such as $\mathrm{Ca}^{2+}, \mathrm{Mg}^{2+}, \mathrm{Al}^{3+}, \mathrm{Mn}^{2+}$ and $\mathrm{V}^{5+}$ ) in the chloride forms and residual $\mathrm{HCl}$. The following study will be concerned with optimizing the effects of $\mathrm{HCl}$ concentration, leaching time, and temperature for maximum extraction of titanium and iron from ilmenite ore.

Table 2: Equilibrium constants for redox half-cell reactions of nitrate ion ${ }^{49}$

\begin{tabular}{lccc}
\hline Reaction & Log $\mathrm{K}$ & $\mathrm{pe}^{0}$ & $\mathrm{E}_{\mathrm{H}}{ }^{0}, \mathrm{~V}$ \\
\hline $\mathrm{NO}_{3}^{-}+2 \mathrm{e}^{-}+2 \mathrm{H}^{+} \leftrightarrow \mathrm{NO}_{2}^{-}+\mathrm{H}_{2} \mathrm{O}$ & 28.6 & 14.3 & 0.843 \\
$\mathrm{NO}_{3}^{-}+3 \mathrm{e}^{-}+4 \mathrm{H}^{+} \leftrightarrow \mathrm{NO}_{(y)}+2 \mathrm{H}_{2} \mathrm{O}$ & 48.4 & 16.1 & 0.952 \\
$2 \mathrm{NO}_{3}^{+}+10 \mathrm{e}^{-}+12 \mathrm{H}^{+} \leftrightarrow \mathrm{N}_{2(y)}+6 \mathrm{H}_{2} \mathrm{O}$ & 210.3 & 21.0 & 1.241 \\
$\mathrm{NO}_{3}^{-}+8 \mathrm{e}^{-}+10 \mathrm{H}^{+} \leftrightarrow \mathrm{NH}_{4}^{+}+3 \mathrm{H}_{2} \mathrm{O}$ & 119.1 & 14.9 & 0.878 \\
$\mathrm{NO}_{2}^{-}+6 \mathrm{e}^{-}+8 \mathrm{H}^{+} \leftrightarrow \mathrm{NH}_{4}^{+}+2 \mathrm{H}_{2} \mathrm{O}$ & - & 15.0 & 0.890 \\
\hline
\end{tabular}

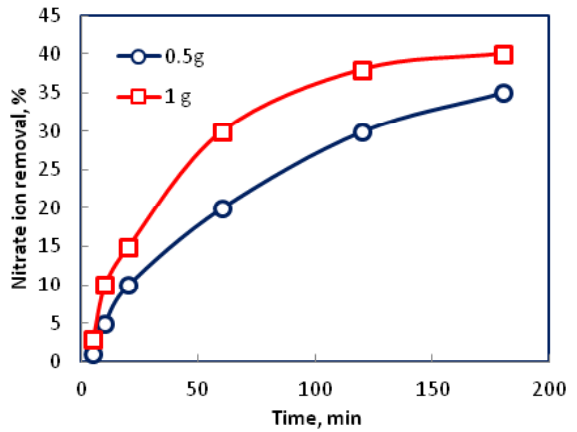

Fig. 10: Effect of shaking time on reduction of nitrate ion with $\mathrm{nZVI-TiO}$, at $\mathrm{pH} 7$

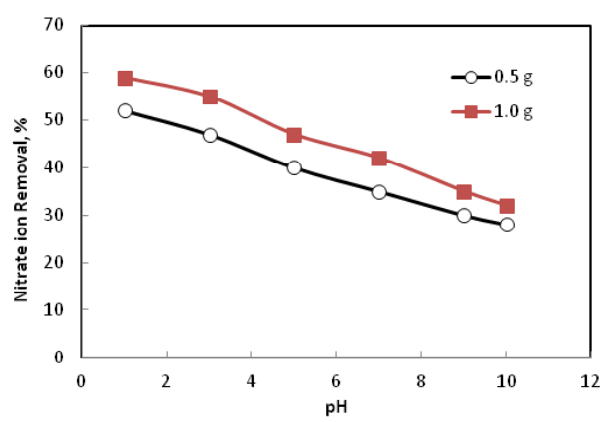

Fig. 11: Effect of pH and nZVI-TiO ${ }_{2}$ mass on reduction of nitrate ion after 3 hours 


\section{Effect of Hydrochloric Acid Concentration}

Figure 5 shows the effect of hydrochloric acid concentration on extraction percentage of titanium and iron from ilmenite ore at $70^{\circ} \mathrm{C}$ for 3 hours. It can be seen from this figure that hydrochloric acid was ineffective for leaching at and less than $20 \%$ where the extraction efficiencies of both metals were as low as $12 \%$ and $2 \%$ for Fe and $\mathrm{Ti}$, respectively. However a sharp increase in extraction was observed at higher acid concentrations. About $94 \%$ and $90 \%$ of Fe and Ti were extracted in $30 \% \mathrm{HCl}$, respectively, and these values very little increased in concentrated $\mathrm{HCl}$. Further studies were performed using $30 \% \mathrm{HCl}$.

\section{Effect of Leaching Time}

Figure 6 shows the effect of leaching time on extraction percentage of titanium and iron from ilmeniteore at $30 \%$ hydrochloric acid and $70^{\circ} \mathrm{C}$. It can be seen from this figure that the extraction efficiencies continuously increased with time for both metal ions up to 3 hours and the extraction was very slightly increased at longer time. About $94 \%$ and $90 \%$ of $\mathrm{Fe}$ and $\mathrm{Ti}$, were extracted at 3 hours, respectively. These values were increased to almost $96 \%$ after 5 hours of leaching time. The next experiments were carried out at $30 \% \mathrm{HCl}$ for 3 hours.

\section{Effect of Leaching Temperature}

Figure 7shows the effect of leaching temperatureon extraction percentage of titanium and iron from ilmeniteore at 30\% hydrochloric acid for 5 hours. It can be seen from this figure that the temperature up to $50^{\circ} \mathrm{C}$ was ineffective for the leaching where the extraction efficiencies were as low as $25 \%$ and $9.5 \%$ for Fe and Ti, respectively. However a sharp increase in extraction (about 95\%) of both metal ions was observed at higher temperature such as $70^{\circ} \mathrm{C}$. Extraction of iron was maintained at high values at higher leaching temperatures than $70^{\circ} \mathrm{C}$, such as $90^{\circ} \mathrm{C}$ and $103^{\circ} \mathrm{C}$ but that of titanium continuously decreased reaching the value of $30 \%$ at $103^{\circ} \mathrm{C}$. This behavior was accompanied by developing a white precipitate of probably hydrated titanium dioxide. Thus the decrease in titanium content in solution was attributed to the hydrolysis reaction of the dissolved titanyl ion $\left(\mathrm{TiO}^{2+}\right)$ yielding a solid $\mathrm{TiO}_{2}$ product asfollows :

$$
\mathrm{TiOCl}_{2}+\mathrm{H}_{2} \mathrm{O} \rightarrow \mathrm{TiO}_{2}+2 \mathrm{HCl}
$$

The leaching products of titanium and iron from ilmenite ore are ferric chloride $\left(\mathrm{FeCl}_{3}\right)$, ferrous chloride $\left(\mathrm{FeCl}_{2}\right)$ and titanyl chloride $\left(\mathrm{TiOCl}_{2}\right)$. The hydrolysis of the latter to $\mathrm{TiO}_{2}$ is known to be favored at low acidity and high temperature. This is consistent with our previous work ${ }^{23}$. It is worth mentioning that at this stage the hydrolysis reaction is not favored since the main aim is to dissolve both metals. Thus, keeping the leaching temperature at $70^{\circ} \mathrm{C}$ is essential to avoid hydrolysis reaction. Any hydrolyzed products will be separated with residue by filtration and will be lost values of titanium.

\section{Application Of the Synthesized nZVI-TiO in Reduction of Nitrate ion Mechanism of Denitrification by nanoscale $n Z V I$ and $\mathrm{nZVI-TiO}$}

In acidic aqueous systems, zero-valent iron is easily oxidized to ferrous ion where the $\mathrm{H}^{+}$ acts as an electron acceptor ${ }^{24}$. The overall process of corrosion in anaerobic $\mathrm{Fe}^{\circ}-\mathrm{H}_{2} \mathrm{O}$ neutral system is described by the following reaction, $\mathrm{Eq}(5)$. But Under aerobic conditions dissolved oxygen would play a role of the electron acceptor in the cathodic half-reaction. In this case, the primary reaction yields only $\mathrm{OH}^{-}$and not $\mathrm{H}_{2}$, $\mathrm{Eq}(6)$ :

$\mathrm{Fe}^{\circ}+2 \mathrm{H}_{2} \mathrm{O} \rightarrow \mathrm{Fe}^{+2}+\mathrm{H}_{2}+2 \mathrm{OH}^{-}$

$2 \mathrm{Fe}^{\circ}+\mathrm{O}_{2}+2 \mathrm{H}_{2} \mathrm{O} \rightarrow 2 \mathrm{Fe}^{+2}+2 \mathrm{OH}^{-}$

In considering the reaction products of nitrate ion reduction, Table 2 lists possible species such as $\mathrm{NO}_{2}^{-}, \mathrm{NO}, \mathrm{N}_{2}$ and $\mathrm{NH}_{4}{ }^{+}$which depend primarily on the redox value $\left(\mathrm{E}_{\mathrm{h}}{ }^{0}\right)$. In view of redox value, the $\mathrm{N}_{2}$ is relatively more difficult to produce $\left(E_{h}{ }^{0}=1.241 \mathrm{~V}\right)$, and the next one is $\mathrm{NO}\left(\mathrm{E}_{\mathrm{h}}{ }^{0}=0.952\right.$ $\mathrm{V})$. Though the $\mathrm{NO}_{2}^{-}$might occur as one of the reaction products $\left(E_{h}{ }^{0}=0.843 \mathrm{~V}\right)$, it easily becomes converted into $\mathrm{NH}_{4}{ }^{+}\left(\mathrm{E}_{\mathrm{h}}{ }^{0}=0.89 \mathrm{~V}\right)$. It appears that $\mathrm{NH}_{4}{ }^{+}$might dominate among these reaction products. As discussed later, the end reduction product was accounted for mostly by $\mathrm{NH}_{4}^{+}$.

A schematic diagram in Fig. 8 shows the possible nitrate ion reduction mechanism. ilmenite leachant is rich in both titanium in the tetravalent state $\left(\mathrm{TiO}^{2+}\right)$ and iron in both divalent $\left(\mathrm{Fe}^{2+}\right)$ and trivalent $\left(\mathrm{Fe}^{3+}\right)$ states. All these species would be in the chloride forms. It is important to note that no hydration of the $\mathrm{TiO}^{2+}$ to the $\mathrm{TiO}_{2}$ species will take place unless all the iron is in the $\mathrm{Fe}^{2+}$ state. Therefore, addition of the calculated amount of iron powder 
reduces the $\mathrm{Fe}^{3+}$ portion to the $\mathrm{Fe}^{2+}$ state. At this stage the $\left(\mathrm{TiO}^{2+}\right)$ species can be easily converted to the white hydrated titania $\left(\mathrm{TiO}_{2}\right)$ by adding the reduced leachant to boiling water with the desired volume ratio. The $\mathrm{pH}$ of the suspension is then adjusted to around 2 to avoid the re-oxidation of iron. Then, the whole $\mathrm{Fe}^{2+}$ in the suspension is reduced to the zero valent state by addition of calculated amount of $\mathrm{NaBH}_{4}$. The precipitated iron sticks to the hydrated $\mathrm{TiO}_{2}$ and the color is changed to black. The formed nZVI-TiO 2 held in suspension for about 2 hours without settling. This product is very active so that if does not separated from the solution it react with water forming the brownish $\mathrm{Fe}(\mathrm{OH})_{3}$. To avoid this, the $\mathrm{nZVI-TiO}$ is quickly separated and thoroughly washed with ethanol and dried. When nZVI-TiO ${ }_{2}$ is contacted with $\mathrm{NO}_{3}^{-}$in water, it will reduce it mostly to $\mathrm{NH}_{4}^{+}$.

\section{Effect of Reducing Material (nZVI or nZVI-TiO ${ }_{2}$ )}

Nitrate ion reduction was firstly tested using either $\mathrm{nZVI}$ or $\mathrm{nZVI}$ loaded on $\mathrm{TiO}_{2}$ surface (nZVI-TiO $)_{2}$. Fig. 9 shows a bar graph comparing the nitrate ion reduction using $0.5 \mathrm{~g}, 1.0 \mathrm{~g}$ and $2 \mathrm{~g}$ of each material at $\mathrm{pH} 7$ for 3 hours. It can be seen that the efficiency of $\mathrm{nZVI-TiO}$ is always superior to that of $\mathrm{nZVI}$.

\section{Effect of Shaking Time}

The effect of shaking time on reduction of nitrate ion using 0.5 and $1 \mathrm{~g} \mathrm{nZVI-TiO}$ at $\mathrm{pH} 7$ is shown in Fig 10. For the two doses, the removal efficiency \% of nitrate ion continuously increased with time till about $120 \mathrm{~min}$ and then slowly increased. These values reached around $35 \%$ and $40 \%$ after

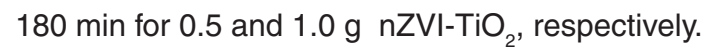

\section{Effect of Solution pH}

The effect of solution $\mathrm{pH}$ ranging from 1 to 7 on the removal efficiency of nitrate ion after 3 hours was performed using two doses of $\mathrm{nZVI-TiO}(0.5 \mathrm{~g}$ and $1.0 \mathrm{~g}$ ) and the results were presented in Fig. 11. The results revealed that the nitrate ion removal efficiency was gradually decreasing with $\mathrm{pH}$ in the acidic and alkaline region. About $50 \%$ and $60 \%$ of nitrate ion could be removed at $\mathrm{pH}=1$ and these values decreased to $30 \%$ and $35 \%$ at $\mathrm{pH}=9$ using

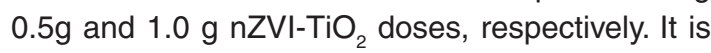
worth mentioning that the performance of $\mathrm{Fe}(0)$ system in terms of iron reactivity and permeability of $\mathrm{Fe}(0)$ bed is negatively affected at above-neutral medium as passivating minerals such as iron oxides, iron sulfides, and carbonate minerals begin to develop on $\mathrm{Fe}(0)$ surface.

\section{CONCLUSION}

In this work, we have succeeded in preparation of a new material composed of hydrated titanium dioxide $\left(\mathrm{TiO}_{2}\right)$ loaded with nano-zero valent iron, was successfully prepared from the inexpensive Egyptian ilmenite ore. The ilmenite ore was found suitable for leaching with hydrochloric acid to produce a solution rich in both titanium and iron ions for further processing, Using 30\% hydrochloric acid at $70^{\circ} \mathrm{C}$ and 5 hours, most of iron and titanium in the ilmenite ore were dissolved. Nano hydrated titania was firstly produced by hydrolysis of the ilmenite leachant and nZVI was subsequently precipitated on its surface by reduction with sodium borohydride in nitrogen atmosphere. The synthesized $\mathrm{nZVI-TiO}$, showed better performance in nitrate reduction than the $\mathrm{nZVI}$ alone, where the latter is easily agglomerates and its activity decreases.

\section{REFERENCES}

1. Wolfe, A.H.; Patz, J.A. Ambio 2002, 31, 120-125.

2. Rao, P.; Mak, M.S.H.; Liu, T.; Lai, K.C.K. ; Lo, I.M.C., Chemosphere 2009, 75, 156-162.

3. Thomson, T.S. Bull. Environ. Contam. Toxicol. 2001, 66, 64-70.
4. Bae, B.U.Y.H. ; Jung, Y.H. ; Han, W.W. ; Shin, H.S. Water Res. 2002, 36, 3330-3340.

5. Schoeman, J.J. ; Steyn, A. Desalination 2003, 155, 15-26.

6. Fernandez-Nava, Y. ; Maranon, E.; Soons, J. ; Castrill, L. Bioresour.Technol. 2008, 99, 
7976-7981.

7. Bhatnagar, A.; Sillanpaa, M. Chem. Eng. J. 2011, 168, 493-504.

8. Hwang, Y.H.; Kim, D.-G. ; Shin, H.-S. J. Hazard. Mater. 2011, 185, 1513-1521.

9. Zhang, Y.; Li, Y.; Hu, L.; Zheng, X. Chem. Eng. J. 2011, 171, 526-531

10. Akhgar, B.N.; Pazouki, M.; Ranjbar, M.; Hosseinnia, A.; Salarian, R. Chem. Eng. Res. Des., 2012, 90, 220-228.

11. Manhique, A.J.; Focke, W.W.; Madivate, C. Hydrometallurgy 2011, 109, 230-236.

12. Zhang, I.; Hu, H.; Liao, Z.; Chen, Q.; Tan, J. Hydrometallurgy 2011, 107, 40-47.

13. Mahmoud M. H. H.; Afifi A. A. I.; Ibrahim I.A. Hydrometallurgy, 2004, 73, 99-109.

14. Mahmoud, M.H.H. Sep. Purif. Technol. 2012, 84, 63-71.

15. Mahmoud, M. H. H.; Ismail, A. A.; Sanad, M. M. S. Chem. Eng. J. 2012, 187, 96-103.

16. Mostafa, N.Y.; Zaki, Z. I.; Heiba, Z. K.; J. Magn.
Mater. 2013, 329, 71-76.

17. Gillham, R.W.; Ohannesin, S. F. Ground Water 1994, 32, 958-967.

18. Liu, C.-C.; Tseng, D.-H.; Wang, C.-Y. J. Hazard. Mater. 2009, 136, 706-713.

19. Ryu, A.; Jeong, S.-W.; Jang, A.; Choi, H. Appl. Catal. B 2011, 105, 128-135.

20. Cho, D.W.; Chon, C.-M.; Jeon, B. H.; Kim, Y.; Khan, M.A.; Song, H.; Chemosphere 2010, 81, 611-616.

21. Vogel, A.I. A Textbook of Quantitative Inorganic Analysis, 1978, 4th ed. Longman, London.

22. Lien, H.L.; Zhang, W.X. Colloid Surf. A-Physicochem. Eng. Asp. 2001, 191, 97-105.

23. Mostafa, N.Y.; Mahmoud, M. H. H.; Heiba, Z. K. Hydrometallurgy 2013, 139, 88-94.

24. Ziajahromi1, S.; Zand, A. D.; Khanizadeh, M. International Conference on Applied Life Sciences (ICALS2012) 2012, Turkey, September 10-12. 